\section{RECENT WORK OF THE AMERICAN BUREAU OF STANDARDS.}

PART i. of vol. ii. of the Bulletin of the Bureau of Standards of the United States contains five papers. The first of these is by Mr. Hyde, on Talbot's law as applied to the rotating sectored disc. The law is stated by Helmholtz as follows :- "If any part of the retina is excited with intermittent light recurring periodically and regularly in the same way, and if the period is sufficiently short, a continuous impression will result, which is the same as that which would result if the total light received during each period were uniformly distributed throughout the whole period."

Much experimental work has been done on the subject leading to somewhat conflicting results. After a theoretical discussion Mr. Hyde describes his own experiments, from which he concludes :-

(1) Talbot's law is verified for white light for all total angular openings from $10^{\circ}$ to $288^{\circ}$ to within a possible error of 0.3 per cent.

(2) The observed deviations from the law for red, green, and blue light are of the same order as those for white light.

The two papers by Dr. Guthe and Mr. Rosa respectively deal with a new determination of the E.M.F. of the Weston and Clark cells by a Gray electrodynamometer. The construction of the instrument and the measurement of its exact dimensions are described in great detail by $\mathrm{Dr}$. Guthe in the first paper, while in the second Mr. Rosa gives the complete theory of the dynamometer employed, and discusses the effects of various errors, such as inaccuracy in the measurement of the dimensions of the coils, irregularities in their winding, and the effect of the opening in the fixed coil through which the suspension of the movable coil passes. The chief results of the work are as follows :-

The E.M.F. of Guthe's " reference standard" cadmium cell, No. 813 , at $21^{\circ} \mathrm{C} .=1.01884$ volts, or only two parts in 100,000 higher than the value given in its Reichsanstalt certificate. The electrochemical equivalent of silver, determined by Guthe in 1904 (Bull. Bur. Stand., vol. i., part i.) in terms of a Weston cell, becomes, when re-calculated to absolute measure, I.11773 mg. per coulomb, when the porous-pot form of coulometer is used.

In the next paper Prof. J. G. Coffin discusses the construction and calculation of inductance standards for Clark University and for the Bureau of Standards. The paper gives in great detail an account of the successive operations. One of the most interesting of these is the use for the accurate grinding of the marble cylinders of an especially fine grinding-machine on a novel principle, which will grind, if required, true cylinders up to $71 \mathrm{~cm}$. diameter, more than 3 metres long, and up to ten tons in weight. The construction and winding of the cylinders presented many of the same problems as the making of the coils of the electrodynamometer referred to above, the coils in both cases being formed of a single layer of wire divided into several parts highly insulated from one another. Following the practical details comes a long mathematical discussion setting forth the methods employed for calculation to the high accuracy required of the inductances of the various parts, the two different formulæ employed giving, for the calculated self-inductance of one of the sections of the Clark University coil, values only differing by one part in four hundred thousand.

The last paper, by Messrs. Hyde and Brooks, is on an efficiency meter for electric incandescent lamps. It consists of an attachment to a photometer on which a scale of watts-per-candle can be arranged, so that the "efficiency" of the lamp to be tested can be directly read off in a very simple manner without calculation. The essential feature consists in the right design to give the desired result of a rheostat in the lamp-circuit, operated by the sliding of one of the photometer carriages. A table of results shows that for a nominal sixteen candle-power lamp over a range of from ten to twenty candles, with accompanying variation of watts-per-candle of from 4.8 to 2.4 , the value for the efficiency as obtained by the instrument and that determined independently by check instruments agreed everywhere to less than I per cent. The value of the arrange- ment lies in the extreme rapidity with which a definite criterion for a large number of specimen lamps can be obtained without troublesome arithmetic.

In part ii. of vol. ii. the first paper, by Mr. Rosa, deals with the calculation of the inductance of single-layer coils. The different types of " summation " and "current-sheet" formulæ due to Rayleigh, Coffin, and Lorenz, and their suitability for use with coils of different shapes, are discussed at length. Examples are also given showing the degree of concordance obtained in definite cases. Tables of general application are calculated, from which the correction term for coils of varying number of turns, made of wire of different diameters, may readily be obtained.

The paper by Mr. H. C. Dickinson is entitled "Heat Treatment of High-temperature Mercurial Thermometers.' It begins by recapitulating the methods of construction of high-range thermometers and the properties and suitability for different ranges of the various high-temperature glasses employed. Tables of the departure of the natural scale of $16^{\prime \prime \prime}$ and $59^{\prime \prime \prime}$ glasses from the gas scale are given up to temperatures of $300^{\circ} \mathrm{C}$. and $500^{\circ} \mathrm{C}$. respectively. The author then describes his own experiments, which deal chiefly with the effect of initial heat treatment on various unannealed thermometers of the different glasses specially constructed for research purposes. The best methods of annealing such thermometers for rendering them as permanent as possible in after use are described. An electric furnace arranged for the purpose is also shown. The following are the more important conclusions of the paper :-

(I) Jena $59^{\prime \prime h}$ borosilicate is the best thermometric glass in use for high temperatures, but it cannot be safely used much above $500^{\circ} \mathrm{C}$

(2) Jena $16^{\prime \prime \prime}$ glass can be used up to $45^{\circ} \mathrm{C}$.

(3) Every thermometer intended for use above $100^{\circ} \mathrm{C}$. should undergo a suitable system of annealing before use. The annealing may be done before the thermometer is filled. A thorough anneal requires four to ten days at $450^{\circ} \mathrm{C}$. The anneal may be followed with advantage by a period of slow cooling of from three to six days.

(4) To prevent the boiling of the mercury in a thermometer, the space above it should be filled with dry nitrogen or carbon dioxide, having a pressure of one atmosphere at $300^{\circ} \mathrm{C}$., of four and a half atmospheres at $450^{\circ} \mathrm{C}$., and of twenty atmospheres at $55^{\circ} \mathrm{C}$.

$\mathrm{Mr}$. Brooks in his paper describes a new potentiometer for E.M.F. and current measurements of intermediate accuracy. It is primarily intended for use in such work as photometry, where rapidity of reading is essential, and where the best deflection instruments give an accuracy, insufficient in most cases.

The feature of the new design is that the potentiometer method is used to balance the bulk of the electrical quantity to be measured, the remainder, perhaps I per cent. of the whole, being shown by a suitable deflection instrument. The design of a successful deflection potentiometer presents several difficulties. In the present case these have been surmounted in a manner similar to that adopted by Stansfield, who was the first to use this type of instrument. The greatest scale error in the new instrument described is 0.02 in 100 volts.

In a paper on spectrum lines as light sources $\mathrm{Mr}$. Bates discusses the structure of the sodium D lines and the green mercury line $\lambda=546 \cdot I \mu \mu$ as sources in polariscopic measurements. Sodium lines obtained in different ways show slight differences. For intense illumination the author prefers sticks of pure $\mathrm{Na}_{2} \mathrm{CO}_{3}$ fed into an oxyhydrogen flame. An echelon spectroscope was used for the study of the lines. The position and intensity of the satellites of the green mercury line were accurately measured. The use of this line is proposed as the standard source for all accurate polariscopic work. A quartz rotation for wave-length $589.25 \mu \mu$ may be obtained by measuring the rotation for the wave-length $546 \cdot \mathrm{I} \mu \mu$, and multiplying it by the constant 0.850944 .

The paper by Mr. Nutting, on polarimetric sensibility and accuracy, hardly permits of useful abstraction. It deals with the intensity and homogeneity of sources used in polarimetry. The mathematical theory of the halfshadow polarimeter is discussed, and formulæ given for calculating the sensibility of the instrument under varying 
conditions. A later paper by the same author describes a pocket spectrophotometer embodying some novel features.

In the paper on the platinum-point electrolytic detector for electrical waves Mr. Austin describes the so-called "barretter" patented by Fessenden, and used by him as detector in wireless telegraphy experiments. It consists of a cell with electrodes, one a fine platinum point, the second a plate, the vessel being filled with an electrolyte giving gaseous decomposition products. When an E.M.F. is applied to such a cell polarisation ensues, so that scarcely any current passes unless the E.M.F. exceeds a certain critical value. When electric oscillations pass through the cell the resistance is decreased, and the current for the moment increases. Conflicting statements have been made by various investigators regarding the behaviour of the instrument, and the author has therefore subjected it to a thorough investigation, employing both ordinary alternating current waves and also the Hertzian waves from the station of the National Electric Signalling Company. The chief conclusions of the research are :-

(I) For the stronger alternating currents used the breaking down in resistance is approximately proportional to the square of the alternating current.

(2) Under favourable conditions and with moderate polarisation the detector is equally sensitive to alternating currents with the point electrode, anode, or kathode.

(3) The resistance of the detector for slowly alternating currents varied from $20,000 \mathrm{ohms}$ to $400 \mathrm{ohms}$, according to the polarising E.M.F. employed.

(4) For electrical waves from a distance the detector is approximately equally sensitive with the point electrode, anode, or kathode, but for waves from a coil in the laboratory some cause appears to annul the sensitiveness of the kathode-point electrode.

The next paper, by Prof. Coffin, is a mathematical investigation on the influence of frequency on self-inductance, and is not capable of useful abstraction.

Messrs. Guthe and Austin then deal with experiments on the magnetic alloys discovered accidentally by Dr. Heusler, and previously investigated at the Reichsanstalt and by Messrs. Fleming and Hadfield. Curves of permeability and inductance were determined for seven different samples, the chemical analysis of which is also given. An ingenious apparatus of high sensitiveness, quite cheap and easy to construct, was designed for study of the magnetic expansion of the alloys. This was capable of detecting changes in length as small as $5 \times \mathrm{ro}^{-7} \mathrm{~mm}$. The investigation is not complete, but the relations between the curves of magnetisation and magnetostriction and between magnetostriction and thermoelectric force are clearly shown. The number and variety of the subjects dealt with in these two instalments of the official publication of the Bureau show that, though only established three years ago, it has already begun to make substantial additions to our knowledge of physics.

J. A. Harker.

\section{RESEARCHES IN STELLAR PARALLAX.'}

SOME years ago Dr. Chase, of the Yale University Observatory, communicated to the Astronomical and Astrophysical Society of America the results of a survey which he had carried out, in collaboration with Dr. Elkin, in order to detect stellar parallax. The number of stars examined was ninety-two, and these were generally selected from a list of stars having an annual proper motion of more than half a second of arc. Of these ninety-two stars, fifteen had a negative parallax, and, presuming that some of the smaller positive values were equally untrustworthy, some sixty were left which exhibited a real parallax amounting to more than $o^{\prime \prime} \cdot 05$. The scheme was one that seemed worthy of further prosecution, since the method employed proved adequate for the purpose of recognising the existence of measurable parallax. Consequently, this work has been very considerably extended, and the recent publication from Yale gives the details of the discussion of no less than $16_{3}$ stars, forming a contribution of the

1 "Parallax Investigations on $x 6_{3}$ Stars mainly of large Proper Motion." By Frederick L. Chase, Mason F. Smith and William L. Elkin. Transac tions of the Astronomical Observatory of Yale University, vol. ii. part i. Pp. 207. (New Haven: The Observatory, 1906.)

No. I 940 , voL. 75$]$ highest importance in parallactic inquiry. Some thirteen years have been devoted to the completion of this work, in which, though Dr. Elkin and Mr. Smith have taken part, the heat and burden of the day has been borne by Dr. Chase. This will be seen from the following tabular statement, which shows both the class of stars examined and the distribution of the work among the several observers :-

Stars with proper motion over

$$
\mathrm{O}^{\prime \prime} \cdot 4 \ldots
$$

Chase $\underset{\text { Elkin }}{\text { Chase Smith }} \underset{\text { Elkin }}{\text { Smith Elkin }}$

Stars selected by De Ball on

account of magnitude ... B Cygnı, Algol, Nova Persei..

Red stars for colour effect

$$
\begin{array}{lllllllllll}
117 & \ldots & 5 & \ldots & 13 & \ldots & 12 & \ldots & 10
\end{array}
$$

I $\ldots-\ldots$ I $\ldots$ I $\ldots-$ $5+\ldots-\ldots-\ldots-\ldots-\ldots-$

$\begin{array}{lllllllllll}\text { Total number of series } \ldots & \mathbf{I} 39 & \ldots & 5 & \ldots & 14 & \ldots & 13 & \ldots & \text { 10 }\end{array}$

The inquiry has been based entirely on measures of distance made with the heliometer. As a rule, two comparison stars were selected on opposite sides of the star the distance of which was to be investigated, and in the direction of maximum displacement by parallax. These comparison stars were as nearly as possible equidistant from the principal star. When the arrangement of the stars did not permit this programme to be carried out completely, special artifices had to be adopted. On the other hand, in the case of stars of particular interest, a larger number of comparison stars was selected. The precautions which Dr. Elkin found necessary in the course of his work on the parallaxes of stars of the first magnitude were applied here, and further reference to these details is unnecessary. Finally, the observations, when collected, usually give for each star twelve complete observations, consisting of four groups of three nights each, taken at those seasons of the year when the parallactic displacement was at its maximum.

A suspicion having been aroused that the measures of distance between two stars of different colours might need an additional correction for refraction, a series of observations was made on some strongly coloured red stars taken from Kruger's "Catalog der farbigen Sterne." A term was introduced into the differential refraction correction of the form $\Delta \beta \tan z \cos (p-q)$, where $p$ is the position, $q$ the parallactic angle, $z$ the zenith distance, and $\Delta \beta$ the colour

\begin{tabular}{|c|c|c|c|c|c|c|c|c|}
\hline Star & & & & $\begin{array}{l}\text { inlour } \\
\text { Scale }\end{array}$ & & $\Delta \beta$ & & Weigh \\
\hline Zruger & 985 & $\ldots$ & $\ldots$ & $6 \cdot 0$ & $\ldots$ & - o.org士o.org & $\ldots$ & $6.3 \cdot 6$ \\
\hline , & 1080 & $\ldots$ & $\ldots$ & $7 \cdot 0$ & $\ldots$ & $+0.005 \pm 0.020$ & $\ldots$ & $64: 4$ \\
\hline ,, & 1078 & $\ldots$ & & $7 \cdot 1$ & $\ldots$ & $+0.009 \pm 0.015$ & $\ldots$ & 16.0 \\
\hline ," & $118 \mathrm{I}$ & $\ldots$ & .. & $7 \cdot 8$ & $\ldots$ & $+0.014 \pm 0.018$ & $\ldots$ & $55 \cdot 7$ \\
\hline & 1108 & $\ldots$ & $\cdots$ & $8 \cdot 7$ & ... & $+0.046 \pm 0.017$ & $\ldots$ & $45^{\circ}$ \\
\hline & & & $\ldots$ & - & $\ldots$ & $-0.003 \pm 0.021$ & $\ldots$ & $55^{\circ}$ \\
\hline
\end{tabular}
effect sought. The several values of $\Delta \beta$ are as follows :-

The authors contend from these figures that the mean light of the red star is apparently refracted less than that of the comparison stars. Whether this conclusion is justified or not, the quantities involved are so small that it can be safely asserted that there is no noticeable vitiation in the parallax results arising from this cause within the probable errors. The remark attributed to Sir David Gill, that the tendency of the heliometer observer is to bring the similarly coloured parts of the star's spectra into coincidence rather than the brightest parts, seems to gain additional support from this investigation.

Of the 163 stars examined, the parallaxes range from $-0^{\prime \prime} \cdot 13$ to $+0^{\prime \prime} \cdot 20$, and the number of negative parallaxes is thirty-six. Considering how wide the net has been spread to catch any star, the proximity of which might be suspected on various grounds, the chance of finding stars closer to us than those which have already been examined grows very slight. The scheme of the stellar universe, so far as the few stars nearest to us are concerned, is taking fairly definite shape, and the scale that has been adopted from measured parallax will probably need no material alteration. Such a conclusion is the more warranted, because the precision attaching to the mean value of a group of results is far greater than that of any individual determination. The authors insist upon this point, and, 